\title{
Defect of platelet function associated with chronic hypoglycaemia
}

\author{
R. A. HUTTON, A. J. MACNAB, and R. P. A. RIVERS \\ From the Department of Haematology, Institute of Child Health, and Departments of Haematology and Paedia- \\ trics, University College Hospital, London
}

\begin{abstract}
Hutton, R. A., Macnab, A. J., and Rivers, R. P. A. (1976). Archives of Disease in Childhood, 51, 49. Defect of platelet function associated with chronic hypoglycaemia. Two patients are described with chronic hypoglycaemia; the first having glucose-6-phosphatase deficiency (type I glycogen storage disease), and the second fructose 1:6-diphosphatase deficiency. Both cases were associated with a bleeding diathesis, a defect of platelet aggregation, and a deficiency of platelet adenine nucleotides. The effect on the platelet abnormalities of a period of normoglycaemia was studied in both patients. Correction of the platelet abnormalities occurred rapidly after stabilization of the blood glucose within the normal range. Normal function persisted for the duration of the normoglycaemia, facilitating diagnostic liver biopsy and surgical procedures. A biochemical explanation for the nucleotide deficicency is suggested.
\end{abstract}

The occurrence of a bleeding disorder attributable to a defect of platelet function has been widely recognized in patients with hypoglycaemia resulting from glycogen storage disease, type 1 (GSD-1). The most comprehensive reports were those of Czapek, Deykin, and Salzman (1973) and Corby, Putnam, and Green (1974). These authors examined a number of platelet and biochemical parameters, but though they concluded that the severity of the platelet defect correlated well with the clinical and biochemical status of their patients, they were unable to identify a specific cause for the platelet abnormality.

We present here the results of investigations of platelet function in two chronically hypoglycaemic patients, one with glucose-6-phosphatase deficiency (GSD-1) and one with fructose 1:6-diphosphatase deficiency (F 1:6 DPase def). Both children were treated over a period of time with continuous glucose infusion (intravenous or nasogastric) and studied before, during, and after this period of normoglycaemia. Our results suggest that the haemostatic defect is due to a deficiency of platelet adenine nucleotides which results from the chronic hypoglycaemia and which can be corrected by maintenance of a normal blood glucose level.

Received 25 April 1975

\section{Materials and methods}

Blood samples were collected by clean venepuncture and mixed with $1 / 10$ th volume of $3.8 \%$ trisodium citrate in plastic tubes. Platelet counts were carried out as described by Hardisty and Ingram (1965). Platelet factor 3 availability was performed by the method of Hardisty and Hutton (1965), platelet retention in a glass-bead column by a modification (Hardisty and Hutton, 1967) of the method of Hellem (1960), and platelet aggregation according to Born (1962). Platelet adenine nucleotides (totals and amount released after 5-minute incubation with $1 \mu \mathrm{mol} / 1$ adrenaline) were measured by the firefly-luciferase method (Holmsen, Holmsen, and Bernhardsen, 1966). Adenosine triand diphosphates, adrenaline, and collagen (bovine Achilles tendon) were obtained from Sigma Biochemicals, and ristocetin was kindly provided by Lundbeck \& Co., Copenhagen.

Controls for these studies were normal healthy adult volunteers and neither these nor the patients had taken any drug known to affect platelet function for at least 10 days before testing.

Case 1. A girl was studied during her eleventh and twelfth years. Her birthweight was $3.80 \mathrm{~kg}$. In the neonatal period she had episodes of sweating and pallor with a blood glucose level of $20 \mathrm{mg} / \mathrm{dl}$ at 16 hours of age, and hyperlipaemia was noted by day 9 of life (total lipids $2 \cdot 24 \mathrm{~g} / 100 \mathrm{ml}$, cholesterol $264 \mathrm{mg} / 100 \mathrm{ml}$ ).

By 5 months there was striking hepatomegaly and frequent episodes of hypoglycaemia, with acidosis and persistent hyperlipaemia. An oral glucose tolerance 
TABLE I

Case 2. Biochemical findings of liver biopsy. Enzyme units expressed as $\mu$ mol of substrate converted/min per $g$ tissue (Eagle et al., 1974)

\begin{tabular}{l|rr}
\hline & Case 2 \\
\hline Glycogen (\%) & $4 \cdot 8$ & Normal \\
Glucose 6-phosphatase & $7 \cdot 6$ & $<4 \cdot 0$ \\
Acid $\alpha$-glucosidase & $2 \cdot 0$ & $3-9$ \\
Glycogen-debranching enzyme with transferase & $0 \cdot 35$ & $1-2$ \\
Phosphorylase & $0 \cdot 2-0 \cdot 6$ \\
Fructose 1:6 diphosphate aldolase & $20 \cdot 0$ & $1 \cdot 9$ \\
Fructose 1-phosphate aldolase & $1 \cdot 3$ & $1-25$ \\
Fructose 1:6 diphosphatase & Nil & $1-2$ \\
\end{tabular}

test showed a fall to very low levels $(12 \mathrm{mg} / \mathrm{dl}) 3$ hours after the load. Liver biopsy has not been performed, a deficiency of hepatic glucose-6-phosphatase having been shown in her brother. She had episodes of excessive bleeding from a laceration of the frenulum when aged 1 year, from a scalp wound at 3 years, haematuria and rectal bleeding at the age of 9 , and frequent epistaxes. In spite of being maintained on a strict 3-hourly regimen of high carboydrate intake (Kelsch and Oliver (1969), $0.3 \mathrm{~g}-0.5 \mathrm{~g}$ glucose/kg per $\mathrm{h}$, day and night), she had poor general health, diminished exercise tolerance, and progressive growth retardation, and at the age of 10 years she was $16 \mathrm{~cm}$ below the $3 \mathrm{rd}$ centile for height.

At this time she was started on a continuous intravenous glucose infusion for 140 days (Macnab, 1974a) in order to observe the effect of maintaining a normal blood glucose level. She then returned to oral carbohydrate supplements, in the same total dose as the intravenous therapy, but given at 2-hourly intervals day and night. This was continued for 7 months. She is currently receiving glucose at the same total dose as a continuous nasogastric infusion.

Case 2. A girl was studied in her first and second years. Her birthweight was $2.95 \mathrm{~kg}$, and the only abnormality noted by the mother in the first months of life was that she became irritable and tachypnoeic if an interval of more than 3 hours elapsed between feeds (cow's milk with no added sugar). At the age of 5 months the child was admitted to hospital with a 5-day history of upper respiratory tract infection with vomiting and feeding difficulty. She was irritable and markedly tachypnoeic. There was clinical evidence of acidosis in relation to feeds, the bicarbonate being lowest $(6.5 \mathrm{mEq} / \mathrm{l})$ immediately before the next feed was due, and associated with hypoglycaemia (blood glucose 15 $\mathrm{mg} / \mathrm{dl})$. The liver extended $6 \mathrm{~cm}$ below the costal margin and there was persistent ketonuria.

She had excessive bleeding from venepuncture sites and two episodes of epistaxis when feeding tubes were being passed. A platelet aggregation defect was shown in association with a deficiency of platelet adenine nucleotides in the presence of a normal platelet count. She was started on a continuous nasogastric infusion of glucose $(0.48 \mathrm{~g} / \mathrm{kg}$ per h) with normal cow's milk feeds 4-hourly, and her blood glucose was maintained by this means within the normal range for a period of 3 months. After this the nasogastric infusion was tailed off, with introduction of the glucose as 3-hourly oral supplements in the same total dose given in addition to her current diet. During the period of normoglycaemia, haemostatic competence was achieved, and an open liver biopsy was performed (Table I), the hepatic enzyme assay showed normal glucose-6-phosphatase and related glycogen pathway enzymes, but a complete absence of fructose 1:6 diphosphatase (Eagle et al., 1974).

\section{Results}

Tables II and III show the changes in biochemistry, and Table IV those in platelet function that occurred on these regimens. Fig. 1 (a, b) shows the platelet aggregation curves in response to in vitro ADP, adrenaline, ristocetin, and collagen. Two curves are shown for each of these four agents -before and during continuous glucose.

In Case 1 the stabilization of blood glucose levels within the normal range, during both periods of continuous therapy, was associated with improvement of her biochemical abnormalities and platelet defect. A marked increase in her growth velocity and improved exercise tolerance and general health also occurred (Macnab, 1974b). These improvements were not maintained during the period on 2-hourly supplements and her bleeding diathesis returned. (A similar defect of platelet aggregation, and a low total nucleotide level (3.33 nmol/ $10^{8}$ platelets, control $7 \cdot 31$, normal range $5-12$ ), and normal ATP-ADP ratio were measured in her brother (also GSD-1), while he was receiving 2hourly oral glucose supplements in the same dose, $0.44 \mathrm{~g} / \mathrm{kg}$ per $\mathrm{h}$ ).

In Case 2 the greatest biochemical improvement occurred on continuous nasogastric glucose, and she became significantly stronger and more active, catching up with her apparently delayed motor milestones within one week. The change to 3hourly supplements caused an initial though 
TABLE II

Case 1. Plasma biochemistry in relation to glucose administration

\begin{tabular}{|c|c|c|c|c|c|c|c|c|}
\hline & \multicolumn{2}{|c|}{ Pretreatment } & \multicolumn{2}{|c|}{$\begin{array}{l}\text { Continuous } \\
\text { intravenous }\end{array}$} & \multicolumn{2}{|c|}{$\begin{array}{l}\text { 2-hourly oral } \\
\text { supplements }\end{array}$} & \multicolumn{2}{|c|}{$\begin{array}{l}\text { Continuous } \\
\text { nasogastric }\end{array}$} \\
\hline & Mean \pm SEM & No. & Mean \pm SEM & No. & Mean \pm SEM & No. & Mean \pm SEM & No. \\
\hline $\begin{array}{l}\text { Glucose }(\mathrm{mg} / 100 \mathrm{ml}) \\
\text { pH } \\
\text { Bicarbonate }(\mathrm{mEq} / \mathrm{l}) \\
\text { Base deficit } \\
\text { Lactate }(\mathrm{mg} / 100 \mathrm{ml}) \\
\text { Pyruvate }(\mathrm{mg} / 100 \mathrm{ml}) \\
\text { Triglyceride glycerol } \\
\quad(\mathrm{mmol} / 1) \\
\text { Cholesterol }(\mathrm{mg} / 100 \mathrm{ml}) \\
\text { Uric acid }(\mathrm{mg} / 100 \mathrm{ml})\end{array}$ & $\begin{array}{c}66 \pm 8 \\
7 \cdot 33 \pm 0 \cdot 02 \\
16 \pm 1 \cdot 4 \\
-8 \pm 0 \cdot 55 \\
50 \\
\\
29 \\
539 \pm 37 \\
8 \cdot 6 \pm 0 \cdot 3\end{array}$ & $\begin{array}{l}6 \\
8 \\
6 \\
8 \\
1\end{array}$ & $\begin{aligned} 85 & \pm 4 \\
7 \cdot 36 & \pm 0 \cdot 01 \\
18 & \pm 0 \cdot 61 \\
-6 & \pm 0 \cdot 39 \\
22 \cdot 3 & \pm 2 \cdot 2 \\
1 \cdot 4 & \pm 0 \cdot 15 \\
8 \cdot 1 & \pm 0 \cdot 6 \\
287 & \pm 11 \cdot 6 \\
6 \cdot 3 & \pm 0 \cdot 54\end{aligned}$ & $\begin{array}{r}38 \\
27 \\
24 \\
23 \\
9 \\
10 \\
13 \\
10 \\
12\end{array}$ & $\begin{aligned} 87 & \pm 11 \\
7 \cdot 36 & \pm 0 \cdot 01 \\
18 & \pm 1 \cdot 1 \\
-7 & \pm 1 \cdot 6 \\
40 \cdot 9 & \pm 6 \cdot 8 \\
2 \cdot 4 & \pm 0 \cdot 52 \\
25 \cdot 3 & \pm 2 \cdot 9 \\
490 & \pm 31 \cdot 8 \\
8 \cdot 6 & \pm 0 \cdot 54\end{aligned}$ & $\begin{array}{r}15 \\
9 \\
7 \\
9 \\
6 \\
4 \\
\\
5 \\
5 \\
6\end{array}$ & $\begin{array}{c}90 \pm 3 \cdot 6 \\
7 \cdot 37 \pm 0 \cdot 01 \\
18 \pm 0 \cdot 6 \\
-6 \pm 1 \cdot 2 \\
35 \cdot 6 \pm 2 \cdot 6 \\
2 \cdot 7 \pm 0 \cdot 3 \\
9 \cdot 6 \pm 0 \cdot 7 \\
326 \pm 12 \cdot 3 \\
7 \cdot 7 \pm 0 \cdot 3\end{array}$ & $\begin{array}{r}15 \\
11 \\
20 \\
11 \\
13 \\
8 \\
13 \\
12 \\
13\end{array}$ \\
\hline
\end{tabular}

TABLE III

Case 2. Plasma biochemistry in relation to glucose administration

\begin{tabular}{|c|c|c|c|c|c|c|}
\hline & \multicolumn{2}{|c|}{ Pretreatment } & \multicolumn{2}{|c|}{$\begin{array}{l}\text { Continuous } \\
\text { nasogastric }\end{array}$} & \multicolumn{2}{|c|}{$\begin{array}{l}\text { 3-hourly oral } \\
\text { supplements }\end{array}$} \\
\hline & Mean \pm SEM & No. & Mean \pm SEM & No. & Mean \pm SEM & No. \\
\hline $\begin{array}{l}\text { Glucose }(\mathrm{mg} / 100 \mathrm{ml}) \\
\text { pH } \\
\text { Bicarbonate }(\mathrm{mEq} / \mathrm{l}) \\
\text { Base deficit } \\
\text { Lactate }(\mathrm{mg} / 100 \mathrm{ml}) \\
\text { Triglyceride glycerol }(\mathrm{mmol} / \mathrm{l}) \\
\text { Cholesterol }(\mathrm{mg} / 100 \mathrm{ml}) \\
\text { Uric acid }(\mathrm{mg} / 100 \mathrm{ml})\end{array}$ & $\begin{aligned} 49 & \pm 7 \cdot 4 \\
7 \cdot 33 & \pm 0 \cdot 02 \\
17 & \pm 2 \cdot 1 \\
-11 \cdot 5 & \pm 0 \cdot 9 \\
48 & \pm 2 \cdot 1 \\
35 \cdot 5 & \pm 2 \cdot 3 \\
321 & \pm 13 \\
8 \cdot 3 & \pm 1 \cdot 1\end{aligned}$ & $\begin{array}{r}22 \\
7 \\
17 \\
7 \\
10 \\
5 \\
4 \\
2\end{array}$ & $\begin{aligned} 75 & \pm 3 \cdot 5 \\
7 \cdot 40 & \pm 0 \cdot 02 \\
19 & \pm 0 \cdot 9 \\
-5 & \pm 0 \cdot 8 \\
33 & \pm 3 \cdot 6 \\
3 \cdot 7 & \pm 0 \cdot 7 \\
136 & \pm 10 \\
5 \cdot 5 & \pm 0 \cdot 8\end{aligned}$ & $\begin{array}{r}15 \\
6 \\
9 \\
6 \\
8 \\
5 \\
4 \\
4\end{array}$ & $\begin{aligned} 72 & \pm 7 \cdot 0 \\
7 \cdot 33 & \pm 0 \cdot 02 \\
16 & \pm 0 \cdot 8 \\
-10 & \pm 0 \cdot 8 \\
49 & \pm 2 \cdot 2 \\
8 \cdot 6 & \pm 0 \cdot 3 \\
204 & \pm 12 \\
5 \cdot 8 & \pm 0 \cdot 3\end{aligned}$ & $\begin{array}{r}22 \\
4 \\
6 \\
4 \\
4 \\
4 \\
5 \\
5\end{array}$ \\
\hline
\end{tabular}

TABLE IV

Platelet function tests in Case 1 (GSD-1) and Case 2 (F1:6 DPase def)

\begin{tabular}{|c|c|c|c|c|c|}
\hline & \multicolumn{2}{|c|}{ Case 1} & \multicolumn{2}{|c|}{ Case 2} & \multirow[b]{2}{*}{ Normal range } \\
\hline & $\begin{array}{l}\text { Pretreatment } \\
\text { (before } \\
\text { continuous } \\
\text { glucose) }\end{array}$ & $\begin{array}{l}\text { Post-treatment } \\
\text { (after } 1 \mathrm{w} \text { of } \\
\text { continuous } \\
\text { glucose) }\end{array}$ & $\begin{array}{l}\text { Pretreatment } \\
\text { (before } \\
\text { continuous } \\
\text { glucose }\end{array}$ & $\begin{array}{l}\text { Post-treatment } \\
\text { (after } 3 \text { w of } \\
\text { continuous } \\
\text { glucose) }\end{array}$ & \\
\hline $\begin{array}{l}\text { Platelet count }\left(10^{3} / \mu \mathrm{l}\right) \\
\text { Platelet factor } 3 \text { availability (\%) } \\
\text { Platelet retention by glass beads (\%) } \\
\text { Platelet adenine nucleotides } \\
\text { Total: (nmol } / 10^{8} \text { platelets) } \\
\text { ATP: (nmol } / 10^{8} \text { platelets) } \\
\text { ADP: (nmol } / 10^{8} \text { platelets) } \\
\text { T:D ratio } \\
\% \text { of total released after } 5 \mathrm{~min} \\
\text { incubation with } 1 \mu \mathrm{mol} / 1 \text { adrenaline }\end{array}$ & $\begin{array}{r}650 \\
15 \\
6 \\
3 \cdot 15 \\
2 \cdot 10 \\
1 \cdot 05 \\
2 \cdot 0 \\
0\end{array}$ & $\begin{array}{r}492 \\
100 \\
15 \\
4 \cdot 87 \\
2 \cdot 69 \\
2 \cdot 18 \\
1 \cdot 2 \\
20\end{array}$ & $\begin{array}{r}424 \\
\quad 9 \\
- \\
3 \cdot 33 \\
2 \cdot 14 \\
1 \cdot 19 \\
1 \cdot 8 \\
6\end{array}$ & $\begin{array}{l}368 \\
75 \\
- \\
6 \cdot 26 \\
4 \cdot 64 \\
1 \cdot 62 \\
2 \cdot 9 \\
26\end{array}$ & $\begin{array}{c}150-400 \\
40-200 \\
18-50 \\
5 \cdot 0-12 \cdot 0 \\
3 \cdot 5-8 \cdot 0 \\
2 \cdot 0-6 \cdot 0 \\
1 \cdot 0-2 \cdot 0 \\
20-53\end{array}$ \\
\hline
\end{tabular}



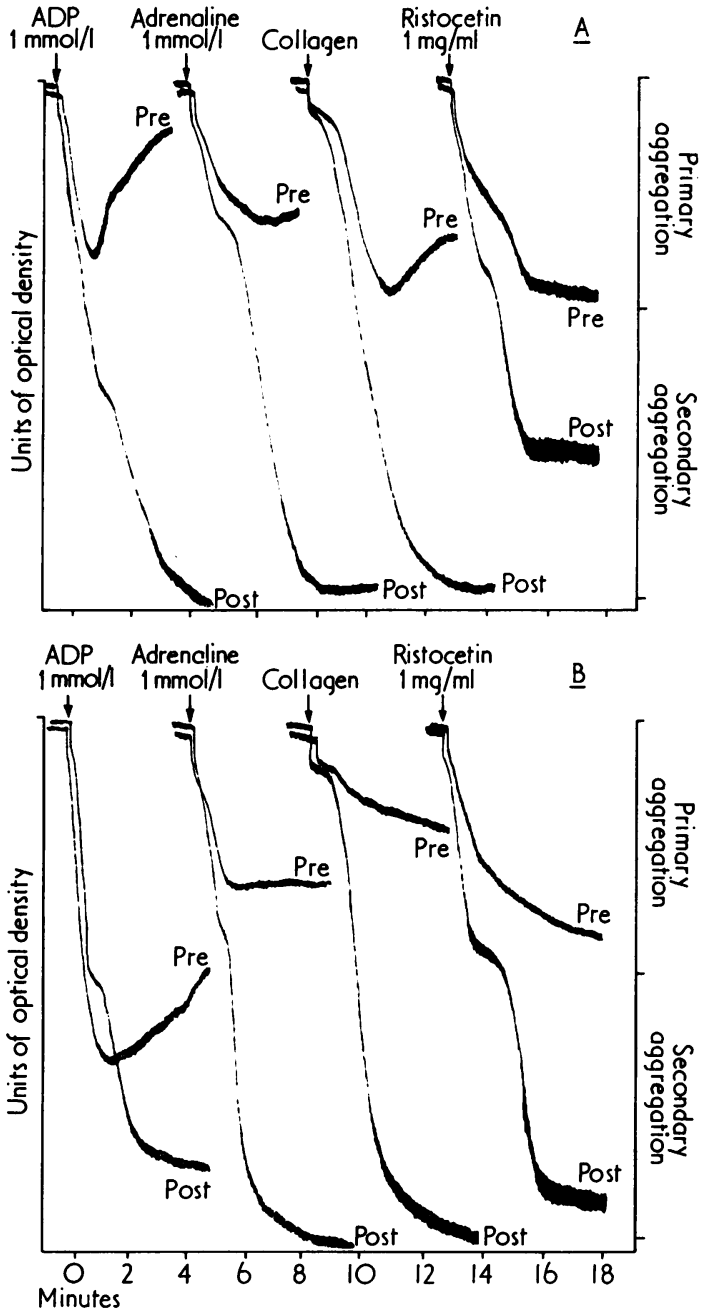

FIG. 1.-Platelet aggregation curves in response to in vitro $A D P$, adrenaline, collagen, and ristocetin in (a) Case 1 GSD-1 and (b) Case 2 F1:6 DPase. Pre, before, Post, during continuous glucose therapy.

temporary physical relapse and a slow but persistent deterioration in her biochemistry. Her platelet function mirrored her physical state, becoming normal on nasogastric glucose, but deteriorating temporarily during the first weeks of the 3-hourly regimen.

Primary platelet aggregation occurred in both children before treatment, but the secondary wave of aggregation which normally follows as a result of the action of ADP released from within the platelets themselves was absent (Fig. 1a, b, Pre). The total nucleotide levels were also low (Table IV), both ATP and ADP being quantitatively reduced, and the release of nucleotides during incubation with adrenaline was decreased.

With normoglycaemia, during continuous glucose treatment, primary and secondary aggregation occurred normally (Fig. 1, Post). Total nucleotides, ATP and ADP levels were within, or close to, normal, and nucleotide release in response to adrenaline was normal. In Case 2 platelet function studies were first repeated 3 weeks after the start of continuous nasogastric glucose, by which time her platelet defect had completely resolved, progressive biochemical improvement being observed up to this time. In Case 1 after one week of normoglycaemia with continuous intravenous glucose, almost complete correction of the platelet abnormalities had occurred. The number of blood samples required to monitor the biochemical progress of these children limited the number of platelet studies which could be performed, and critical time course experiments were not carried out. For this reason also only platelet aggregation and total platelet adenine nucleotide levels were followed throughout treatment.

These nucleotide levels are shown in Figs. 2 and 3. In GSD-1 (Fig. 2, Case 1), these correlate well with the efficiency of the treatment, being normal when mean glucose levels were maintained within the normal range by intravenous or intragastric infusion, and falling again on the 2-hourly regimen, when significant periods of hypoglycaemia occurred with a marked deterioration of her biochemistry. During the continuous nasogastric infusion, a period of rapid growth occurred and for a 4-week period ( $\star$ Fig. 2) the dose of glucose infused per $\mathrm{kg}$ fell below the dose which Case $1 \mathrm{had}$ been receiving previously $(0.44 \mathrm{~g} / \mathrm{kg}$ per $\mathrm{h})$. This period was also associated with a deterioration of plasma biochemical values and a fall in platelet nucleotides, but restoration of the original dose again produced improvement of biochemistry and total nucleotide levels.

In Case 2 (Fig. 3, F 1:6 DPase deficiency) correlation is less clear. A definite initial improvement occurred with the normoglycaemia of continuous nasogastric glucose, and a deterioration was seen during the first 6 weeks on 3-hourly supplements. Since then total nucleotide levels and aggregation curves have remained normal during health. However, during a 5-day hospitalization with gastroenteritis three epistaxes occurred, and the tendency to prolonged bleeding after venepuncture was again observed.

Although her biochemical status deteriorated on changing from continuous nasogastric glucose to 


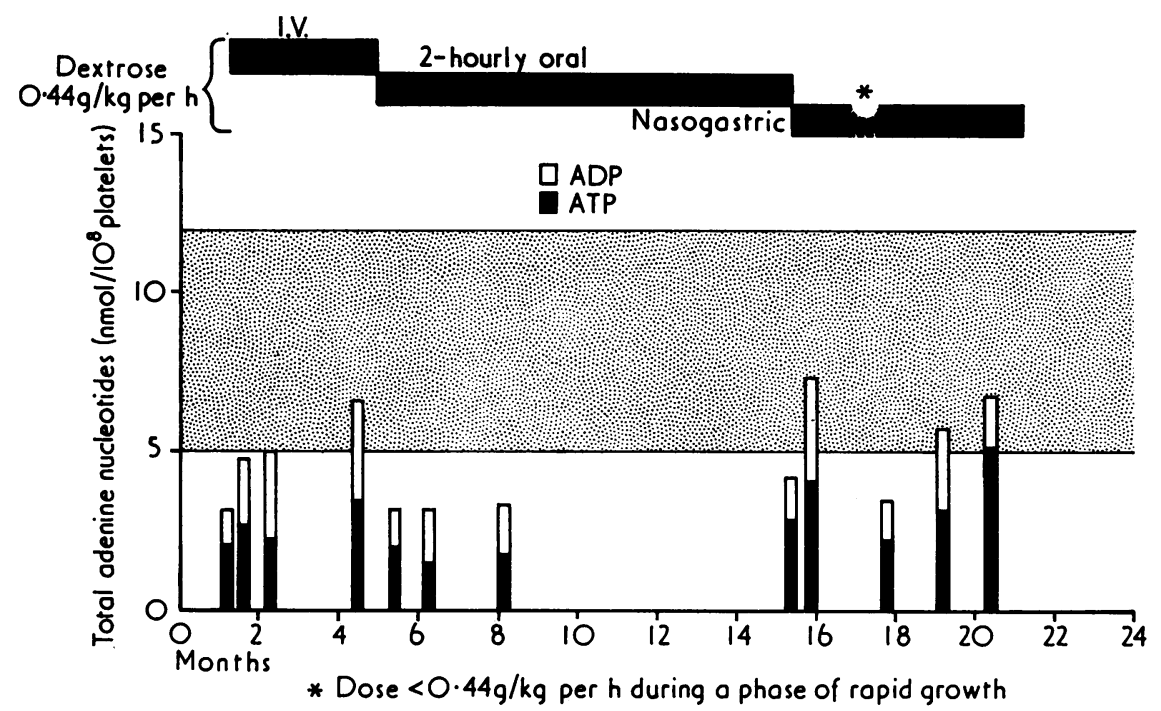

FIG. 2.-Case 1. Total platelet adenine nucleotide levels and ADP:ATP ratios, during 3 treatment regimens.

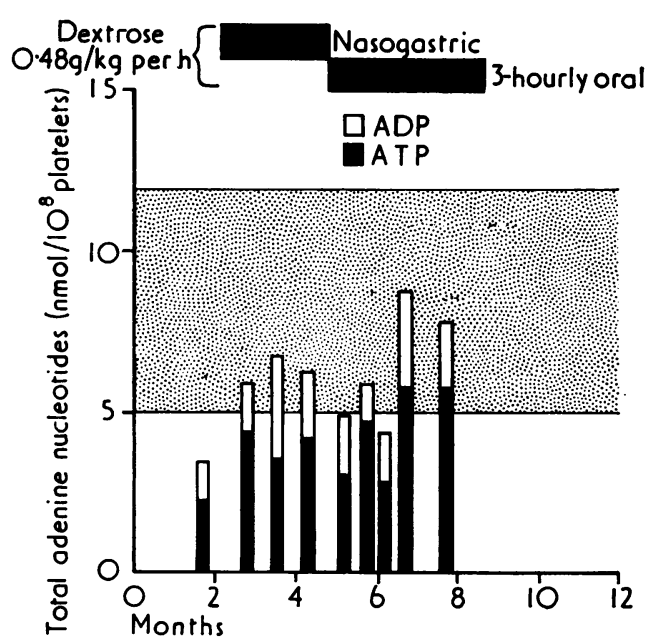

FIG. 3.-Case 2. Total platelet adenine nucleotide levels and ADP:ATP ratios, during 2 treatment regimens.

3-hourly supplements, it remained significantly better than in the pretreatment period. In contrast to Case 1, the change from continuous to intermittent glucose was not associated with a return of her biochemical status to pretreatment levels. In addition, though low blood glucose levels have been recorded before most 3-hourly feeds the child remains clinically well, not showing the pallor, sweating, and irritability characteristic of the pretreatment period. This suggests that a less severe pattern of hypoglycaemia is now occurring which is compatible with haemostatic competence.

\section{Discussion}

Cause of hypoglycaemia. In the absence of the enzyme glucose-6-phosphatase (G-6-Pase) which characterizes GSD-1, the liver is unable to generate glucose from glycogen via glucose-6phosphate (G-6-P). This leads to a severe degree of hypoglycaemia, and the accumulation of G-6-P. As a result of the low blood glucose there is increased mobilization and de novo synthesis of lipids, and consequent hypercholesterolaemia, hypertriglyceridaemia, hyperlipoproteinaemia, and ketosis (Drash and Field, 1971). The high level of cellular G-6-P favours glycolysis and lactic acid production, which together with the ketosis causes metabolic acidosis.

A deficiency of fructose 1:6 diphosphatase in the liver prevents the conversion of fructose, triose phosphates, glycerol, and glucogenic amino acids, such as alanine, to glucose (Baker and Winegrad, 1970). This block in gluconeogenesis results in accumulation of F 1:6 DP and hypoglycaemia after consumption of all the available glycogen. The lipid mobilization, lactic acidosis, and other biochemical abnormalities arise by a similar mechanism to that described above in GSD-1, but glycogen formation, storage, and breakdown are normal.

Nature of platelet defect. Although some gluconeogenesis from noncarbohydrate sources has been shown to occur in platelets, the majority of the 
platelet glucose is derived from the plasma (Gross and Schneider, 1971). The mechanism by which this occurs is obscure; the process is temperaturedependent, no active transport mechanism has been shown and it does not occur against a concentration gradient. It is most probably due to a process of altered diffusion (McDonagh et al., 1968) similar to that seen in red cells (Faust, 1960).

Chronic hypoglycaemia, whatever its cause, will produce within the platelet a low glucose level, decreased glycolysis, and a reduction in the formation of energy-rich ATP. The fall in ATP production is secondary to a reduced pyruvate concentration, this being the substrate for the oxidative pathway from which the majority of platelet ATP is derived. It is generally assumed, the respiratory quotient of platelets being 1, that carbohydrate metabolism is their sole source of energy. Platelet glycogen in GSD-1 has been reported as normal (Czapek et al., 1973) or increased (Linneweh et al., $1962 / 63)$, but in the absence of G-6-Pase this glycogen cannot be converted to glucose. No information regarding platelet glycogen in F-1:6DPase deficiency is available to us.

On injury to a blood vessel, platelets come into contact with collagen fibres in the vessel wall to which they adhere; after adhesion, the platelets undergo a release reaction in which certain specific cytoplasmic constituents are expelled into the surrounding medium. In terms of the haemostatic mechanism the most important of these is ADP, derived from the storage pool of nucleotides not directly involved in the cell's metabolism. This ADP induces platelet aggregation, leading to the formation of a platelet plug. Enhancement of clot formation is brought about by the activation of platelet factor 3 which becomes available as a consequence of this aggregation.

Defects of the platelet release reaction usually result in a bleeding tendency, there are two main groups of these defects (Hardisty, 1972). The first 'storage-pool deficiency' is seen as an hereditary abnormality, either as an isolated defect or in association with albinism or certain other conditions. Total platelet adenine nucleotide levels are low due to the inability of the platelets to retain nucleotides in the storage pool, and the ADP level is particularly depressed leading to a high ATP-ADP ratio. In the second group the total platelet nucleotide level and ATP-ADP ratio are normal, but there is a failure of nucleotide release. This condition is most frequently secondary to the ingestion of drugs, particularly aspirin, or due to retained metabolites in uraemic patients, but may occur as a primary platelet disorder.
The results reported here form a third type of release reaction defect in which the total nucleotide level of the platelets is decreased, with the ATPADP ratio generally within normal limits. This suggests that both the storage pool and the metabolic pool are reduced, though we have no direct measurement of the storage pool levels. Our nucleotide results are somewhat at variance with those of Czapek et al. (1973), who found that ATP levels were normal in some of their patients, and with those of Corby et al. (1974) who reported normal ADP levels in 2 of their patients. Neither of these authors reported nucleotides fully, and the former group used different methods of estimation, which may account for the differences observed.

Although the mechanisms have not been fully elucidated it seems that the energy-dependent functions of the platelets, aggregation, uptake, release, and clot retraction are dependent on the platelets' metabolic pool of ATP (Day and Holmsen, 1971). A decrease of metabolic ATP resulting from hypoglycaemia would therefore have farreaching effects on platelet function. The usually normal ATP-ADP ratios and the results of glucose therapy in our 2 patients support this concept of dual deficiency.

Both our patients showed low platelet nucleotide levels when chronically hypoglycaemic. Both had a different enzyme defect (in F 1:6 DPase deficiency, hypoglycaemia occurs in spite of an intact pathway for glycogen breakdown to glucose). Platelet function studies and total adenine nucleotide levels became normal during treatment with glucose which maintained blood glucose levels within the normal range in the case of GSD-1, and which significantly reduced the severity of the hypoglycaemia in the case of F 1:6 DPase deficiency.

While marked improvement of other biochemical parameters occurred as a result of the glucose therapy, the effect of such changes on platelet function has not been established.

Lamberth, Warriner, and Batchelor (1974) observed similar defects of aggregation in vitro to those in our patients, when platelet-rich plasma was rendered acidic $(p \mathrm{H} 7 \cdot 16-7 \cdot 29)$ by the addition of $\mathrm{HCl}$. However, there is no significant difference in the in vivo $\mathrm{pH}$ values among the four treatment regimens in GSD-1, or the three treatment periods in F 1:6 DPase deficiency. We suggest that chronic hypoglycaemia alone is the factor responsible for the defective platelet aggregation of type I glycogen storage disease, that this aggregation defect is due to a depletion of the total platelet adenine nucleotide level and is readily reversible by maintenance of normoglycaemia. 
This work was carried out with the aid of grants from the National Fund for Research into Crippling Diseases and the Medical Research Council, which are gratefully acknowledged. We thank Professor R. M. Hardisty for advice, and Professor L. B. Strang and Dr. S. Tucker for permission to study their patients.

\section{REFERENCES}

Baker, L., and Winegrad, A. I. (1970). Fasting hypoglycaemia and metabolic acidosis associated with deficiency of hepatic fructose-1: 6-diphosphatase activity. Lancet, $2,13$.

Born, G. V. R. (1962). Aggregation of blood platelets by adenosine diphosphate and its reversal. Nature, 194, 927.

Corby, D. G., Putnam, C. W., and Greene, H. L. (1974). Impaired platelet function in glucose-6-phosphatase deficiency. Fournal of Pediatrics, 85, 71 .

Czapek, E. E., Deykin, D., and Salzman, E. W. (1973). Platelet dysfunction in glycogen storage disease type I. Blood, 41, 235.

Day, H. J., and Holmsen, H. (1971). Concepts of the platelet release reaction. Series Haematologica, Vol. IV, No. 1, p. 3. Munksgaard, Copenhagen.

Drash, A., and Field, J. (1971). The glycogen storage diseases. DM; Disease-a-Month, October.

Eagle, R., Macnab, A. J., Ryman, B., and Strang, L. B. (1974). Liver biopsy data on a child with fructose 1:6-diphosphatase deficiency that closely resembled many aspects of glucose-6phosphatase deficiency (Von Gierke's type I glycogen storage disease). Biochemical Society Transactions, 2, 1118.

Faust, R. G. (1960). Monosaccharide penetration into human red blood cells by an altered diffusion mechanism. Fournal of Cellular and Comparative Physiology, 56, 102.

Gross, R., and Schneider, W. (1971). Energy metabolism. The Circulating Platelet, p. 123. Ed. by S. A. Johnson. Academic Press, London.

Hardisty, R. M. (1972). Haemostatic functions of platelets and their disorders. Scientific Basis of Medicine. Annual Reviews, p. 222.

Hardisty, R. M., and Hutton, R. A. (1965). The kaolin clotting time of platelet-rich plasma: a test of platelet factor-3 availability. British fournal of Haematology, 11, 256.

Hardisty, R. M., and Hutton, R. A. (1967). Bleeding tendency associated with a 'new' abnormality of platelet behaviour. Lancet, 1, 983.

Hardisty, R. M., and Ingram, G. I. C. (1965). Bleeding DisordersInvestigation and Management, p. 255, Blackwell, Oxford.

Hellem, A. J. (1960). The adhesiveness of human blood platelets in vitro. Scandinavian Fournal of Clinical Investigation, 12, Suppl. 51.

Holmsen, H., Holmsen, I., and Bernhardsen, A. (1966). Microdetermination of ADP and ATP in plasma with the firefly luciferase system. Analytical Biochemistry, 17, 456.

Kelsch, R. C., and Oliver, W. J. (1969). Studies on dietary correction of metabolic abnormalities in hepatorenal glycogenosis. Pediatric Research, 3, 160.

Lamberth, E. L., Jr., Warriner, R. A., and Batchelor, E. D. (1974). Effect of metabolic acidosis and alkalosis on human platelet aggregation induced by epinephrine and ADP. Proceedings of the Society for Experimental Biology and Medicine. 145. 743.

Linneweh, F., Löhr, G. W., Waller, H. D., and Gross, R. (1962/63). Úber die diagnose von glykogenosen aus der Glukose-6Phosphatase-Aktivitat und dem glykogengehalt der thrombozyten. Enzymologia Biologica et Clinica, 2, 188.

Macnab, A. J. (1974a). Type I glycogenosis: effects of prolonged intravenous dextrose infusion on growth and plasma biochemistry. (Abst.) Pediatric Research, 8, 136.

Macnab, A. J. (1974b). Increased growth velocity in type I glycogen storage disease during reversal of metabolic abnormalities, by two periods of prolonged dextrose infusion. Pediatria XIV. Proceedings of 14th International Congress of Pediatrics, Vol. 10: Metabolism, p. 195.

McDonagh, R. P., Burns, M. J., Delaimi, K. E., and Faust, R. G. (1968). Sugar penetration into human blood platelets. Fournal of Cellular Physiology, 72, 77.

Correspondence to Dr. A. J. Macnab, Paediatric Department, University College Hospital, Huntley Street, London WC1E 6AU. 